\title{
Impact of transthoracic echocardiography at district hospital level
}

\author{
W F Bedeker, ${ }^{1} \mathrm{MB}$ ChB; A S Lachman, ${ }^{2} \mathrm{FCP}(\mathrm{SA})$, FACC; M Borkum, ${ }^{3} \mathrm{MB}$ ChB, FCP (SA); \\ D Hellenberg, ${ }^{1} \mathrm{MB}$ ChB, MFamMed, FCFP (SA); C S Cupido, ${ }^{2} \mathrm{MB}$ ChB, FCP (SA) \\ ${ }^{1}$ Division of Family Medicine, School of Public Health and Family Medicine, Faculty of Health Sciences, University of Cape Town, South Africa \\ ${ }^{2}$ Victoria Hospital, Wynberg, Cape Town, South Africa \\ ${ }^{3}$ Department of Medicine, Groote Schuur Hospital, Cape Town, South Africa
}

Corresponding author: W F Bedeker (wfbedeker@gmail.com)

Background. The use of and demand for echocardiography (ECHO) has increased worldwide. In developed countries, this has not translated into improved access outside tertiary centres. Previous studies have favoured the appropriate use of ECHO over its clinical impact, limiting generalisability to resource-constrained settings.

Objectives. To assess the impact of an ECHO service at district hospital level in Cape Town, South Africa.

Methods. A prospective, cross-sectional study was performed. A total of 210 consecutive patients, referred to the ECHO clinic over a 5 -month period, were recruited. Transthoracic ECHO was evaluated in terms of its indication, new information provided, correlation with the referring doctor's diagnosis and subsequent management plan. Impact included the escalation and de-escalation of treatment, as well as usefulness without a change in management.

Results. The results show that $83.8 \%$ of the patients' management was impacted on by echocardiography. Valvular lesions were the main indication. The most frequent contribution was information provided towards the diagnosis of heart failure and assessment after myocardial infarction. Of the echocardiograms, $56.2 \%$ confirmed the referring doctor's diagnosis, yet were still associated with a significant impact. The rational prescription of medication had the major impetus, followed by de-escalation of therapy and screening patients to determine referral to a tertiary facility.

Conclusion. ECHO has a positive impact on patient management outside tertiary settings, where the definition of impact appears to be different. The value of a normal study, screening prior to upstream referral and usefulness irrespective of change have been established. This should alert policy makers against restriction of access to ECHO and promote training of personnel in its use.

S Afr Med J 2015;105(10):817-822. DOI:10.7196/SAMJnew.8102

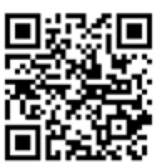

The use of and demand for echocardiography (ECHO) have shown a marked increase worldwide. ${ }^{[1]}$ As a 'special' investigation it has the potential to provide accurate haemodynamic as well as anatomical information non-invasively at the bedside. ${ }^{[1-3]}$

Developing countries are showing a steady rise in non-communicable diseases (NCDs), with cardiovascular diseases proving the largest burden in South Africa (SA). ${ }^{[4,5]}$ The dual burden of communicable diseases and NCDs is disproportionately affecting vulnerable lowerincome groups in urban settings. ${ }^{[4]}$ Ironically, patients accessing hospitals with the least available specialist expertise have been shown to have the highest number of comorbidities. ${ }^{[6]}$ Access to investigations such as ECHO, traditionally and often exclusively at the hands of specialist cardiologists, remains restricted and uneven in SA.

Recent advances in the developed world include open-access echocardiography (OAE), which is requested and the results acted on by general practitioners, hand-held devices, and point-of-care studies by non-cardiologists. ${ }^{[2,7-9]}$ Apart from their usefulness in screening patients, appropriate care can be implemented at an earlier stage and waiting times for, or referrals to, tertiary care can be reduced. The main limitation for the roll-out of ECHO to primary healthcare settings is the lack of training of personnel. ${ }^{[10]}$

A few recent studies have reviewed the utility of ECHO in large, mainly tertiary centres in the developed world. ${ }^{[11-13]}$ The use is driven mainly by appropriate-use criteria (AUC). These AUC identify common clinical scenarios in which ECHO can be applied and aim at improving health outcomes by means of the equitable allocation of resources in cardiovascular imaging. ${ }^{[14]}$ There is a paucity of data regarding the impact of ECHO in sub-Saharan Africa. Various definitions of impact and the different concepts of a district or general hospital limit the generalisability to resource-constrained areas, where, paradoxically, the clinical impact of ECHO may be of more value than the traditionally accepted clinical indications.

\section{Objectives}

To assess the clinical impact of an ECHO service in a district hospital in SA. Further conclusions on the demand to access and need for training in echocardiography were possible.

\section{Methods}

A prospective, descriptive, cross-sectional study was conducted at Victoria Hospital, a district-level hospital in Cape Town, SA, serving a patient population (in 2014) of nearly 600000 , mainly of low and middle socioeconomic status. The study cohort consisted of patients referred to the once-weekly ECHO service during the 14-week period between September 2013 and January 2014.

Recruitment of study participants was achieved on the day of the prebooked ECHO appointments. All in- and outpatient referrals were considered, regardless of age and comorbidities. Patients unable to give written consent were excluded. Only screening transthoracic echocardiography (TTE) was included. It was performed by a registered cardiologist, accredited to perform ECHO. 
EpiCalc (freeware, version 1.02, 2000) was used to calculate the sample size. It was assumed that $80 \%$ of management decisions would change following results of the ECHO. To achieve a confidence level of $95 \%$ with a precision of $5 \%$ (i.e. a margin of error of $10 \%$ ), a sample size of 245 patients was required.

Data were collected prospectively, as the ECHO was performed. A questionnaire concerning patient characteristics and medical history was completed by the participant with the help of a research assistant. The cardiologist who performed the ECHO completed a second questionnaire in order to establish the impact of the ECHO by assessing the indication for the investigation, new information obtained, correlation with the referring doctor's diagnosis and the management plan thereafter. AUC were used to classify indications explicitly. The average waiting period was randomly calculated on four dates, reviewing the time until the next available appointment.

The cardiologist used a Toshiba Nemio machine with an adult ECHO probe PST25AT $(1.8-4.2 \mathrm{mHz})$. The patients were screened in the supine and left lateral positions. Examinations were viewed in real time and done in standard transthoracic views, parasternal long and short axis with apical four-chamber views; subxyphoid views were included when indicated. M-mode, 2D and colour flow Doppler were utilised. The ejection fraction was measured using the Teicholz method. Regional wall motion was visually evaluated in the abovementioned views. Continuous Doppler was not available on the machine, but colour flow Doppler was used when necessary. M-mode recording was done and printed out when deemed necessary, but not stored. The ECHOs performed were for screening purposes only and were not standard transthoracic evaluations. Even though some patients had repeated TTE, most patients did not have a baseline standard study.

Impact was classified according to adapted criteria (Table 1). ${ }^{[11-13]}$

\section{Statistical analysis}

Data were captured with Excel version 14.0.0 (Microsoft, USA, 2011) and analysis was performed on Stata 12.0 (Statacorp, USA, 2011). Where data were not normally distributed (e.g. age), a Kruskal-Wallis test was used. The Pearson's $\chi^{2}$ test or Fisher's exact test (if the expected frequency of a group was smaller than five) was used to calculate the statistical significance of the different proportions. Statistical significance was accepted as $p<0.05$. Prevalence ratios were then calculated. Absent data were perceived as missing completely at random, as categorical data were collected as tick sheets.

\section{Ethical considerations}

This study was approved by the Health Science Research Ethics Committee of the University of Cape Town (HREC 382/2013). Each participant gave written consent to participate in the study, and a study number was allocated to each in order to ensure confidentiality.

\section{Results}

A total of 210 participants were recruited (Fig. 1). Approximately one-third

\begin{tabular}{|c|c|c|}
\hline Impact level & & Description \\
\hline \multirow[t]{10}{*}{ Active } & \multirow[t]{6}{*}{ Escalation } & More rational drug therapy \\
\hline & & Confirmation of vegetation \\
\hline & & Cardioversion required \\
\hline & & $\begin{array}{l}\text { Referred for further imaging (angiography or nuclear } \\
\text { medicine study) }\end{array}$ \\
\hline & & Referred to tertiary cardiology services \\
\hline & & $\begin{array}{l}\text { Other referrals: palliative care programme, disability grant } \\
\text { assessment }\end{array}$ \\
\hline & De-escalation & $\begin{array}{l}\text { Reassurance of normal study, omitting further testing or } \\
\text { avoiding further referral }\end{array}$ \\
\hline & \multirow{3}{*}{$\begin{array}{l}\text { No change, but } \\
\text { clinically useful }\end{array}$} & Contesting clinical suspicion/diagnostic value \\
\hline & & Repeat echo advised/monitoring purpose \\
\hline & & Cleared for theatre \\
\hline \multirow[t]{2}{*}{ No impact } & & Continue current management plan \\
\hline & & Confirming clinical suspicion with no change in management \\
\hline
\end{tabular}

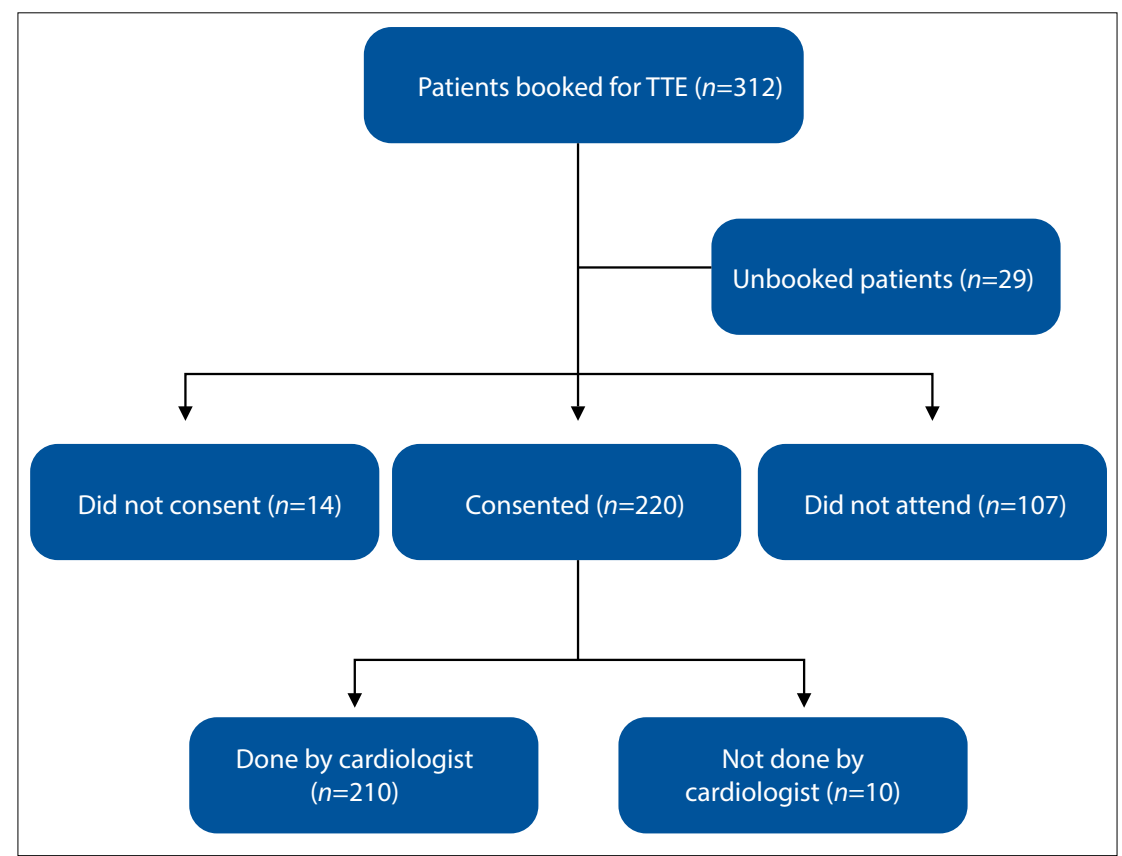

Fig. 1. Recruitment of participants. of the patients did not attend on their appointment date. The majority of the participants were referred by the Department of Medicine, either from the ward or via the Outpatient Department (Table 2).

Self-reported and documented comorbidities included 9 HIV-positive participants (4.3\%), 5 with rheumatic heart disease (2.8\%) and 4 with a previous mitral valve replacement $(2.3 \%)$, all associated with impact. It was not documented whether these valve replacements were initially indicated for rheumatic heart disease. Of the participants, 131 (62.4\%) had a history of smoking, one-third of these indicating a current smoking habit. Of those older than 
16 years, 34 (17.4\%) were employed, while $29(13.8 \%)$ were receiving disability grants and $63(30.0 \%)$ were pensioners.

An average number of 17 ECHOs were performed per clinic during the study period. The average waiting time until the next available appointment was 89 days.

\section{Clinical utility and association with impact}

We found that $83.8 \%$ of TTEs had an impact on the patient's management. In total, $51.0 \%$ of ECHOs resulted in an escalation of management, and $19.0 \%$ in de-escalation, while $13.8 \%$ had an impact without a change of management.
Table 2. Characteristics of patients referred for TTE

\begin{tabular}{|c|c|c|c|}
\hline & Total impact & No impact & Total \\
\hline Age (years), median (range or mean; SD) & $52(2-86)$ & $60(25-87)$ & $53(50 ; 20.13)$ \\
\hline Male, $n(\%)$ & $90(50.8)$ & $18(54.5)$ & $108(51.4)$ \\
\hline Female, $n(\%)$ & $87(49.1)$ & $15(45.4)$ & $102(48.6)$ \\
\hline Employed (>16 years old), $n(\%)$ & $27(16.7)$ & $7(21.2)$ & $34(17.4)$ \\
\hline Pensioner, $n(\%)$ & $49(27.7)$ & $14(42.4)$ & $63(30.0)$ \\
\hline Receiving DG, $n(\%)$ & $24(13.6)$ & $5(15.1)$ & $29(13.8)$ \\
\hline Currently inpatient, $n(\%)$ & $48(27.1)$ & $5(15.1)$ & $53(25.2)$ \\
\hline \multicolumn{4}{|l|}{ Referring facility, $n(\%)$} \\
\hline Medical ward & $76(42.9)$ & $16(48.5)$ & $92(43.8)$ \\
\hline ED & $34(19.2)$ & $7(21.2)$ & $41(19.5)$ \\
\hline MOPD & $32(18.1)$ & $9(27.3)$ & $41(19.5)$ \\
\hline POPD & $12(6.8)$ & - & $12(5.7)$ \\
\hline $\mathrm{CHC}$ & $12(6.8)$ & - & $12(5.7)$ \\
\hline $\mathrm{DH}$ & $5(2.8)$ & - & $5(2.4)$ \\
\hline Private sector & $1(0.6)$ & - & $1(0.5)$ \\
\hline Other & $4(2.3)$ & $1(3.0)$ & $5(2.4)$ \\
\hline Unknown source of referral & $1(0.6)$ & - & $1(0.9)$ \\
\hline \multicolumn{4}{|l|}{ Comorbidities, $n(\%)$} \\
\hline Hypertension & $91(51.4)$ & $28(84.8)$ & $119(56.6)$ \\
\hline Ischaemic heart disease & $54(30.5)$ & $13(39.4)$ & 67 (31.9) \\
\hline Hypercholesterolaemia & $49(27.7)$ & $12(36.4)$ & $61(29.5)$ \\
\hline Diabetes mellitus & $40(22.6)$ & $9(27.3)$ & $49(23.3)$ \\
\hline Cardiac failure & $30(18.2)$ & $6(18.2)$ & $36(17.1)$ \\
\hline Atrial fibrillation & $16(9.0)$ & $2(6.1)$ & $18(8.6)$ \\
\hline COPD & $15(8.5)$ & $2(6.5)$ & $17(8.1)$ \\
\hline Known cardiomyopathy & $13(7.3)$ & $3(0.1)$ & $16(7.6)$ \\
\hline Stroke & $12(6.8)$ & $1(3.0)$ & $13(6.2)$ \\
\hline HIV & $9(5.1)$ & - & $9(4.3)$ \\
\hline Thyroid disease & $8(4.5)$ & - & $8(3.8)$ \\
\hline Obesity & $4(2.3)$ & $2(6.1)$ & $6(2.9)$ \\
\hline Rheumatic heart disease & $5(2.8)$ & - & $5(2.4)$ \\
\hline Mitral valve replacement & $4(2.3)$ & - & $4(1.9)$ \\
\hline \multicolumn{4}{|l|}{ Habits, $n(\%)$} \\
\hline Ex-smoker & $70(39.5)$ & $15(45.4)$ & $85(40.5)$ \\
\hline Current smoker & $38(21.5)$ & $8(24.2)$ & $46(21.9)$ \\
\hline Alcohol & $30(16.9)$ & $9(27.3)$ & $39(18.6)$ \\
\hline Drugs (ex or current) & $16(9.0)$ & $1(3.0)$ & $17(8.1)$ \\
\hline Total, $n(\%)$ & $176(83.8)$ & $34(16.2)$ & $210(100.0)$ \\
\hline
\end{tabular}

Valvular lesions were the main indication for referral (Table 3). Only one patient's indication was seen as inappropriate when compared with the AUC. ${ }^{[14]}$

The major contribution of TTE was the information provided to aid the diagnosis of heart failure $(29.0 \%)$ and ischaemic heart disease (23.8\%) (Table 4). Of all participants, one-third had impaired left ventricular (LV) function. Three cases of apical thrombus were identified after myocardial infarction, which resulted in the initiation of anticoagulation therapy.

The most common valvular lesions identified, in order of prevalence, are listed in Table 4. Of these, mitral stenosis, discerning aortic scleroses from stenosis, identifying non-pathological murmurs and aortic regurgitations were statistically significantly associated with clinical impact. In addition to the five participants known to have rheumatic heart disease prior to the TTE, three further cases were diagnosed, the total prevalence being $3.8 \%$ in our study cohort.

Six participants were diagnosed with cor pulmonale and four with pulmonary hypertension; none of these was known to be suffering from chronic obstructive pulmonary disease.

Despite the fact that $56.2 \%$ of all TTEs $(n=118)$ confirmed the referring doctor's diagnosis, these ECHOs were still significantly linked to impact (confidence interval 0.64 $0.80)$. In $39.1 \%(n=82)$ the pre-referral diagnosis was contested and in $4.8 \%(n=10)$ it was unknown. Of the 34 TTEs that did not have an impact, $88.2 \%(n=30)$ correlated with the pre-referral diagnosis.

\section{Spectrum of clinical impact}

TTE was found to be most useful in the rational prescription of medication $(n=80)$. Twenty-seven participants, one-fifth of those who had an escalation in management, required referral to tertiary services (Fig. 2). Of these upstream referrals, 9 patients were referred for surgery: 5 were for valve replacements, 3 for the correction of atrial septal defects and 1 for surgery of an atrial myxoma. Three patients, with severe disease, required referral to the hospital's social worker for a disability grant.

De-escalation of care, with return to primary healthcare services, was recommended in 40 cases. Fifteen participants were offered reassurance for non-pathological murmurs and six participants for idiopathic chest pain, preventing further testing or referral to a higher level of care. The remainder benefited in that TTE ruled out cardiac sources of emboli, structural causes for 
Table 3. Indications and their association with clinical impact

\begin{tabular}{|c|c|c|c|c|}
\hline & $\begin{array}{l}\text { Total impact } \\
n(\%)\end{array}$ & $\begin{array}{l}\text { No impact } \\
n(\%)\end{array}$ & $\begin{array}{l}\text { Total } \\
n(\%)\end{array}$ & $\begin{array}{l}\text { Prevalence ratio } \\
\text { 95\% CI }\end{array}$ \\
\hline Evaluation of valvular function & $66(37.5)$ & $7(20.6)$ & $73(34.8)$ & $1.01-1.26$ \\
\hline Unknown cause of heart failure & $47(26.7)$ & $7(20.6)$ & $54(25.7)$ & $0.93-1.19$ \\
\hline Post-myocardial infarction (for regional wall motion abnormalities) & $26(14.8)$ & $9(26.5)$ & $35(16.7)$ & $0.61-0.90$ \\
\hline Suspected hypertensive heart disease & $18(10.2)$ & $16(47.1)$ & $34(16.2)$ & $0.38-0.72$ \\
\hline Rhythm abnormality on ECG & $31(17.6)$ & $1(2.9)$ & $32(15.2)$ & $1.08-1.31$ \\
\hline Cardiomegaly, found clinically and radiologically, not known with CCF & $22(12.5)$ & $2(5.9)$ & $24(11.4)$ & $0.97-1.27$ \\
\hline Known cardiomyopathy & $13(7.4)$ & $3(8.8)$ & $16(7.6)$ & $0.79-0.89$ \\
\hline Evaluation of chest pain of unknown cause & $14(7.9)$ & $2(5.9)$ & $16(7.6)$ & $0.86-1.27$ \\
\hline $\begin{array}{l}\text { History suggestive of arrhythmia, e.g. palpitation, light-headedness, } \\
\text { presyncope or syncope }\end{array}$ & $14(7.9)$ & - & $14(6.7)$ & $0.78-0.88$ \\
\hline Evaluation of cardiovascular source of embolus & $9(5.1)$ & $1(2.9)$ & $10(4.8)$ & $0.87-1.34$ \\
\hline Other & $21(11.9)$ & $1(2.9)$ & $22(10.5)$ & - \\
\hline Total & $176(83.8)$ & $34(16.2)$ & $210(100.0)$ & \\
\hline
\end{tabular}

\section{Table 4. New information found on TTE}

\begin{tabular}{|c|c|c|c|c|}
\hline & $\begin{array}{l}\text { Total impact } \\
n(\%)\end{array}$ & $\begin{array}{l}\text { No impact } \\
n(\%)\end{array}$ & $\begin{array}{l}\text { Total } \\
n(\%)\end{array}$ & $\begin{array}{l}\text { Prevalence ratio } \\
\mathbf{9 5 \%} \mathrm{CI}\end{array}$ \\
\hline $\begin{array}{l}\text { Detection of LV systolic } \\
\text { dysfunction }\end{array}$ & $57(32.4)$ & $9(26.5)$ & $66(31.4)$ & $0.93-1.18$ \\
\hline $\begin{array}{l}\text { Cause of heart failure } \\
\text { established }\end{array}$ & $28(15.9)$ & $6(17.6)$ & $34(16.2)$ & $0.82-1.16$ \\
\hline $\begin{array}{l}\text { Cause of heart failure } \\
\text { confirmed }\end{array}$ & $24(13.6)$ & $3(8.8)$ & $27(12.9)$ & $0.92-1.24$ \\
\hline $\begin{array}{l}\text { Wall motion abnormality } \\
\text { found }\end{array}$ & $28(15.9)$ & $4(11.8)$ & $32(15.2)$ & $0.91-1.22$ \\
\hline $\begin{array}{l}\text { Wall motion abnormality } \\
\text { ruled out }\end{array}$ & $12(6.8)$ & $6(17.6)$ & $18(8.6)$ & $0.48-0.92$ \\
\hline LV hypertrophy & $29(16.5)$ & $14(41.2)$ & $43(20.5)$ & $0.54-0.82$ \\
\hline Congenital heart disease & $4(2.3)$ & - & $4(1.9)$ & $0.79-0.89$ \\
\hline LV aneurysm & $1(0.6)$ & - & $1(0.5)$ & $0.78-0.89$ \\
\hline \multicolumn{5}{|l|}{ Valvular lesions } \\
\hline Mitral regurgitation & $56(26.7)$ & $5(15.1)$ & $61(29.0)$ & $1.01-1.25$ \\
\hline Tricuspid regurgitation & $34(16.2)$ & $5(15.1)$ & $39(18.6)$ & $0.90-1.19$ \\
\hline $\begin{array}{l}\text { Aortic sclerosis discerned } \\
\text { from aortic stenosis }\end{array}$ & $21(11.9)$ & $9(26.5)$ & $30(14.3)$ & $0.55-0.88$ \\
\hline Aortic stenosis & $17(8.1)$ & $3(9.1)$ & $20(9.5)$ & $0.83-1.23$ \\
\hline Functional murmur & $15(8.5)$ & - & $15(7.1)$ & $0.77-0.88$ \\
\hline Mitral stenosis & $14(6.7)$ & - & $14(6.7)$ & $0.78-0.88$ \\
\hline Aortic regurgitation & $8(3.8)$ & - & $8(3.8)$ & $0.79-0.89$ \\
\hline Total & $176(83.8)$ & $34(16.2)$ & $210(100.0)$ & \\
\hline
\end{tabular}

perceived arrhythmia (symptomatic or on electrocardiogram), pulmonary hypertension and infective endocarditis.

ECHOs performed on 29 participants resulted in no change in management, but provided clinically useful information. Of these, two-thirds $(n=16)$ were advised to have follow-up ECHOs (implying ongoing monitoring of their current condition). Eleven participants had ECHOs that

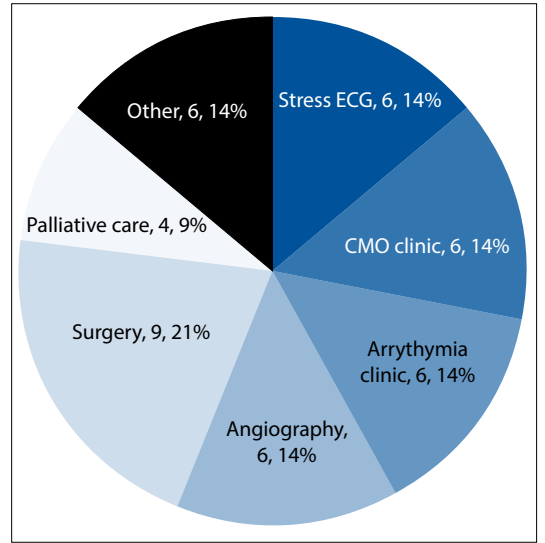

Fig. 2. Upstream referrals (impact or upstream referral clinic, number of cases, percentage of escalated management) after ECHO. (CMO = cardiomyopathy; $E C G=$ electrocardiogram. $)$

contested the referring doctor's diagnosis and two were deemed fit for surgery as part of an anaesthetic work-up.

Behavioural advice, for example direct advice on alcohol consumption, weight reduction and smoking cessation, was documented but not analysed. Three female patients with postpartum cardiomyopathy were advised against future pregnancies.

\section{Discussion}

We found that the majority (83.8\%) of ECHOs had a positive impact on patients referred to a district hospital - a proportion much higher than that previously reported in developed country settings of $32-76 \%{ }^{[12,13]}$ The diversity of patients' ages, comorbidities and sources of referral revealed the broad value of this investigative modality. 
The value of a prospective study is that single ECHO assessment in a non-tertiary setting can immediately address a focused, clinical question or suspicion raised, and may have an immediate impact. Our definition of impact is different from previous larger impact studies, undertaken either in tertiary settings or in community hospitals with specialised cardiology services. ${ }^{[12,13]}$ A few older studies done at district hospitals either reviewed the impact more than 30 years ago, using only M-mode ECHO, or focused on intensive care units. ${ }^{[3,15,16]}$ The lack of generalisability to current district hospital practice seems obvious, especially in resource-constrained settings.

We have established the role of ECHO in causing de-escalation in therapy and continuation of management at district hospital level. This potential for decreasing referral to tertiary specialists seems similar to other studies. ${ }^{[7,9,16]}$ Previous studies have cautioned against undervaluing a study with normal findings. ${ }^{[8,11,17]}$ This latter benefit was confirmed in $32.9 \%(n=69)$ of all the participants referred, without escalating management. Its use in screening prescreened patients is evident, with a particularly high impact level in all paediatric patients, mainly aiding in de-escalation of services relating to a murmur that had been auscultated prior to referral. This has been undervalued by previous studies. ${ }^{[12,15]}$ Our study has shown that impact does not necessarily translate into a change in management many patients without a change in clinical status require follow-up, which is seen as a valid indication in itself in early and late stages of cardiac disease. ${ }^{[14]}$

The major change in management proved to be rational prescription of medication. The other main benefit was determining which patients required up-referral to tertiary services, e.g. for cardiac surgery.

AUC are not used in SA. Nevertheless, only one participant's indication could not be classified according to AUC, as the referral was for possible cardiac cause for seizures. This indicates the high level of appropriate use of ECHOs in our district hospital. The most common indication was suspected valve disease. Its significance could not be statistically linked to impact, perhaps owing to the small sample size achieved. New information gathered was nevertheless significant for mitral stenosis and aortic regurgitation, mirroring the finding of a previous audit of the beneficial value of ECHO in assessing diastolic (more than systolic) murmurs. ${ }^{[15]}$ Three adult participants but no paediatric patients were newly diagnosed with rheumatic heart disease. A recent study in SA has shown the decrease in rheumatic heart disease in children in SA, which may be due to improved access to healthcare and an improved socioeconomic environment. ${ }^{[18]}$ The use of ECHO as a screening tool for rheumatic heart disease has yet to be translated into impact on prognosis and effective secondary prophylaxis for subclinical disease. Results suggest that adults may benefit from screening more than children. ${ }^{[19]}$

Of all indications for ECHO, assessment of regional wall motion abnormalities and suspected hypertensive heart disease were statistically significantly associated with impact. The value of $\mathrm{ECHO}$ in defining prognosis in these two conditions has been described previously. ${ }^{[20,21]}$ One study found that the evaluation of wall motion abnormalities constitutes the most statistically significant, independent prognostic data provided by TTE. ${ }^{[20]}$ Although screening of all hypertensive patients has been recommended, as left ventricular hypertrophy itself implies a worse prognosis, ${ }^{[22]}$ others assert that ECHO confirmation would probably not intensify the treatment of the hypertension itself. ${ }^{[22,23]}$

In our study, heart failure was the major indication for ECHO, as was the case in a systematic review of patients referred for OAE from primary care. ${ }^{[23]}$ The role of TTE in providing new information in this context is nonetheless unsurpassed, by detecting LV dysfunction and either establishing or confirming the cause of failure. ${ }^{[17]}$ This is of particular value in our setting, where heart failure is usually diagnosed and monitored by clinical means only. Despite two-thirds of the cohort having a smoking history, low numbers of cases of COPD and its complications were reported. Screening for and assessing cardiac complications, such as cor pulmonale and pulmonary hypertension, in patients with COPD can be useful, as both infer increased morbidity and mortality. ${ }^{[24]}$ The diagnosis of a clinically unsuspected atrial myxoma in this small cohort was a finding that would otherwise have remained undetected.

Discrepancies between the results of the TTEs and the assessment of the referring clinician prior to the test were confirmed, as per previous studies. ${ }^{[25,26]}$ It appears that the positive impact of TTE is independent of the clinical accuracy of the referring doctor. On the other hand, a lack of impact was nonetheless associated with accurate pre-referral assessment. This may indicate that a thorough history and physical examination may lessen the need for a diagnostic test. ${ }^{[2]}$ Thirty-nine percent of the ECHOs disproved the pre-referral diagnosis.

In some of the participants who had had previous TTEs, repeat ECHO nevertheless had an important clinical impact. An earlier study found that the added diagnostic value of a repeat ECHO is significantly independent of whether the test had been performed previously. ${ }^{[25]}$

Approximately one-fifth of patients were referred from the hospital's emergency department; this may indicate the need for training in question-focused, point-of-care studies. A review of TTEs performed by non-cardiologists showed an active change in management in $16-37 \%$ of patients in an emergency setting. ${ }^{[9]}$

Failure of referral of patients from primary healthcare facilities was found despite doctors being free to refer patients directly for TTEs; it is not clear whether the medical staff were unaware of the existence of the service. Notably, among the few patients in this study cohort who were referred from community healthcare settings, the ECHOs had an important impact.

The waiting time for the next available appointment was six times as long as the recommended time period of 2 weeks advised by the National Institute for Care Excellence guidelines for patients with chronic heart failure and after myocardial infarction. ${ }^{[27]}$ A Dutch study of OAE reports a waiting time of 5 weeks. ${ }^{[7]}$ In developing countries, a lack of resources and scarce skills may be the reason for this long waiting time. The poor socioeconomic status of our participants, including pensioners and those receiving disability grants, suggests a reliance on public sector facilities. The poor attendance for TTE appointments shows the undervaluing of this restricted resource. Non-attendance is often due to lack of funds for transport. Having this service only at a distant tertiary centre may add to poor attendance.

\section{Study limitations}

Our study does have limitations. The participants were referred from the hospital ward or outpatient departments and had been prescreened after being admitted via the emergency department or referred from a primary healthcare facility. This may overvalue the impact owing to a lower incidence of negative findings. Patients with acute cardiac illness, such as heart failure or myocardial infarction, may be more likely to benefit from ECHO. The inclusion of hospitalised patients probably increased the likelihood of appropriate referrals by doctors. ${ }^{[1]}$ The ECHOs were performed by an experienced cardiologist, with this specialist assessment in itself likely to have an impact on patient management, causing impact to be overestimated. The risk of possible bias exists, as the 
cardiologist was involved in the clinical decision-making process and management of participants. The study size was smaller than initially anticipated, mainly because of patients defaulting on their appointments.

Following the participants' completion of the questionnaires, all data were checked to correlate with the clinical information in their folders. This allowed for more accurate analysis of the patient characteristics and the echocardiograms as well as their indications. Fifteen patient folders were missing and were not checked retrospectively.

The downstream risks of TTE, such as incorrect interpretation and residual anxiety despite a normal study, should not be disregarded. ${ }^{[1,14,28]}$

It would be important to gain insight into whether clinical impact and changes in management eventually translate into improved health outcomes in primary healthcare. These effects could be assessed in a follow-up study. Other than its clinical impact, the cost implications of a restricted resource should be studied. The benefits of more accurate diagnosis, improving rational drug prescription and decreasing the burden on the tertiary healthcare system should be evaluated. A patient-centred approach can also evaluate patients' own perception of impact on their illness.

\section{Conclusion}

Echocardiography had a positive impact on patient management in a district hospital setting. Limited access for patients may negatively impact on their management, as a valuable contribution of TTEs to overall management was found. A normal ECHO is important in offering reassurance to patients and diagnostic assistance to the referring doctor, and aiding in referral back to the primary level of care. In the overburdened public health sector, where continuity of care is frequently a problem, it may reduce time and costs. By providing an ECHO service in non-tertiary settings, patients can be screened and more appropriately referred to scarce upstream specialists and subspecialist departments.

Training in interpretation and accreditation in the use of ECHO should be a priority for teaching and academic facilities, especially for personnel working in general, emergency and family medicine. The prospect of hand-held devices would definitely enhance access, but may compromise quality.

Policy makers should be alerted to the added value offered by an ECHO assessment. The rapidly growing burden of NCDs should encourage investment in such service-based interventions to local communities. ${ }^{[4]}$ District hospitals can establish protocols in the communities they serve, to assist with procurement and referrals from primary health care.

Acknowledgements. H Carrara assisted with the statistical analysis. D Lunga collected data as research assistant.

Funding. A research grant was obtained from the Department of Public Health and Family Medicine of the University of Cape Town.

\section{References}

1. Feigenbaum H. Evolution of echocardiography. Circulation 1996;93(7):1321-1327. [http://dx.doi. org/10.1161/01.CIR.93.7.1321]

2. Chung J. Echocardiography in 2009: State of the art. J Invasive Cardiol 2009;21(7):346-351

3. Brown AK, Anderson V. The use of cross-sectional echocardiography in a general hospital. J Postgrad Med 1980;56:221-228.

4. Mayosi BM, Flisher AJ, Lalloo UG, et al. The burden of non-communicable diseases in South Africa. Lancet 2009;374(9693):934-947. [http://dx.doi.org/10.1016/S0140-6736(09)61087-4]

5. Puoane TR, Tsolekile LP, Calbick S, et al. Chronic non-communicable diseases in South Africa: Progress and challenges. In: Padarath A, English R, eds. South African Health Review 2012/13. Durban: Health Systems Trust, 2013. http://www.hst.org.za/publications/south-african-healthDurban: Health Systems Trust, 2013,

6. De Vries E, Raubenheimer P, Kies B, Burch VC. Acute hospitalisation needs of adults admitted to public facilities in the Cape Town Metro district. S Afr Med J 2011;101(10):760-764.

7. Van Gurp N, Boonman-De Winter LJM, Meijer Timmerman Thijssen DW, Stoffers HEJH. Benefits of an open access echocardiography service: A Dutch prospective cohort study. Neth Heart J 2013;21(9):399-405. [http://dx.doi.org/10.1007/s12471-013-0416-9]

8. Rao A, Henton D, Walsh J. Evolving trends in open access echocardiography - experience over eight years. http://www.priory.com/med/echo.pdf (accessed 13 August 2013).

9. Haji DL, Royse A, Royse CF. Review article: Clinical impact of non-cardiologist-performed transthoracic echocardiography in emergency medicine, intensive care medicine and anaesthesia. Emerg Med Australas 2013;25(1):4-12. [http://dx.doi.org/10.1111/1742-6723.12033]

10. Xiao HB, Sethi A. Community echocardiography. Clinical Focus Primary Care 2006;1(3):88-93.

11. Alqarqaz M, Koneru J, Mahan M, Ananthasubramaniam K. Applicability, limitations and downstream impact of echocardiography utilization based on the appropriate-use criteria for transthoracic and transoesophageal

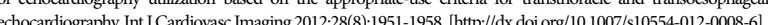

2. Mar impact of transthoracic echocardiography. JAMA Intern Med 2013;173(17):1600-1607. [http://dx.doi. org/10.1001/jamainternmed.2013.8972]

13. Ballo P, Bandini F, Capecchi I, et al. Application of 2011 American College of Cardiology Foundation/ American Society of Echocardiography Appropriateness Use Criteria in hospitalized patients referred for transthoracic echocardiography in a community setting. J Am Soc Echocardiogr 2012;25(6):589598. [http://dx.doi.org/10.1016/j.echo.2012.03.006]

14. Douglas PS, Garcia MJ, Haines DE, et al. ACCF/ASE/AHA/ASNC/HFSA/HRS/SCAI/SCCM/SCCT/ SCMR 2011 appropriate use criteria for echocardiography: A report of the American College of Cardiology Foundation Appropriate Use Criteria Task Force, American Society of Echocardiography, American Heart Association, American Society of Nuclear Cardiology, Heart Failure Society of America, Heart Rhythm Society, Society for Cardiovascular Angiography and Interventions, Society of Critical Care Medicine, Society of Cardiovascular Computed Tomography, and Society for Cardiovascular Magnetic Resonance. J Am Coll Cardiol 2011:57(9):1126-1166. Published online before print 19 November 2010. [http:///dx.doi.org/10.1016/j.jacc.2010.11.002]

15. Pollick C. Echocardiography in a district general hospital. Postgrad Med J 1978:54(631):297-301. [http://dx.doi.org/10.1136/pgmi.54.631.297]

16. Orme RML, Oram MP, McKinstry CE. Impact of echocardiography on patient management in the intensive care unit: An audit of district general hospital practice. Br J Anaesth 2009;102(3):304-344. http://dx.doi.org/10.1093/bja/aen378]

17. Chambers J, Fuat A, Liddiard S, et al. Community echocardiography for heart failure: A consensus statement from representatives of the British Society of Echocardiography, British Heart Failure Society, CHD collaborative and Primary Care Cardiovascular Society. Br J Cardiol 2004;11(5):399-402.

18. Cilliers AM. Rheumatic fever and rheumatic heart disease in Gauteng on the decline: Experience at Chris Hani Baragwanath Academic Hospital, Johannesburg, South Africa. S Afr Med J 2014;104(9):632-634. [http://dx.doi.org/10.7196/SAMJ.8318]

19. Zühlke L, Mayosi BM. Echocardiographic screening for subclinical rheumatic heart disease remains a research tool pending studies of impact of prognosis. Curr Cardiol Rep 2013;15(3):343. [http://dx.doi. org/10.1007/s11886-012-0343-1]

20. Madsen BK, Egeblad H, Hojberg S, et al. Prognostic value of echocardiography compared to other clinical findings. Cardiology 1995;86(2):157-162. [http://dx.doi.org/10.1159/000176863]

21. Weissman NJ, Ristow B, Schiller NB. Role of echocardiography in acute myocardial infarction. http://www.uptodate. com/contents/role-of-echocardiography-in-acute-myocardial-infarction.htm (accessed 10 December 2013).

22. Amidon TM, Chou TM, Foster E, Kee LL. Role of echocardiography in primary care medicine: Controversies in hypertension, atrial fibrillation, stroke and endocarditis. West J Med 1996:164(3):269275. [http://dx.doi.org/10.1111/j.1540-8175.2000.tb01151]

23. Khunti K. Systematic review of open access echocardiography for primary care. Eur J Heart Fail 2004;6(1):79-83. [http://dx.doi.org/10.1016/j.ejheart.2003.10.002]

24. Gupta NK, Kamar Agrawal R, Srivastav AB, Ved ML. Echocardiographic evaluation of heart in chronic obstructive pulmonary disease and its co-relation with the severity of disease. Lung India 2011;28(2):105-109. [http://dx.doi.org/10.4103/0970-2113.80321]

25. Krumholz HM, Douglas PS, Goldman L, Waksmonski C. Clinical utility of transthoracic twodimensional and Doppler echocardiography. J Am Coll Cardiol 1994;24(1):125-131. [http://dx.doi. org/10.1016/0735-1097(94)90552-5]

26. Mangione S, Nieman LZ. Cardiac auscultatory skills of internal medicine and family practice trainees. A comparison of diagnostic proficiency. JAMA 1997;278(21):717-722. [http://dx.doi.org/10.1001/ a comparison of diagnostic

27. Chronic heart failure: Management of chronic heart failure in adults in primary and secondary care. http:// www.nice.org.uk/guidance/cg108/chapter/key-priorities-for-implementation (accessed 29 October 2014). 28. McDonald IG, Daly J, Jelinek VM, Panetta F, Gutman JM. Opening Pandora’s box: The unpredictability of reassurance by a normal test. BMJ 1996;313(7053):329-332.

Accepted 25 June 2015. 